\title{
CARDIOVASCULAR REACTIONS TO EMOTIONAL STIMULI. EFFECT ON THE CARDIAC OUTPUT, ARTERIOVENOUS OXYGEN DIFFERENCE, ARTERIAL PRESSURE, AND PERIPHERAL RESISTANCE ${ }^{1}$
}

\author{
By JOHN B. HICKAM,2 WALTER H. CARGILL, AND ABNER GOLDEN \\ (From the Department of Medicine, Duke University, Durham, North Carolina, and the \\ Department of Medicine, Emory University, Atlanta, Georgia)
}

(Received for publication October 8, 1947)

\section{INTRODUCTION}

Emotional disturbances may have a profound effect on the circulation, causing changes in the heart rate, cardiac output ( 1 and 2 ), blood pressure, tone of peripheral vessels, and the electrocardiogram (3). This is particularly true of the emotional state which may develop in persons who find themselves in a hazardous situation. For present purposes this emotional state is termed "anxiety," although it is recognized that other reactions such as resentment or anger may also occur, depending upon the individual and the circumstances. In any study on unanesthetized human subjects, changes produced by anxiety may mask completely the physiologic or pharmacologic effects which are obvious in a relaxed subject. In the interpretation of experimental data, objective criteria by which it can be established, or even suspected, that anxiety is having an effect on cardiovascular function are useful. It is also of importance to clinical medicine to have further information concerning the degree to which anxiety may affect certain aspects of cardiovascular function and on the mechanisms by which the effects of organic cardiovascular disease may be simulated or intensified by anxiety. It is the purpose of the present report to make a contribution in both of these directions.

\section{METHODS}

The interpretation of data relating anxiety to circulatory changes is handicapped by the absence of a reliable objective means of measuring the degree of anxiety induced or even of detecting the presence of anxiety at all. In judging variation in response to anxiety, it is difficult to distinguish between variation in the intensity of the stimulus and in the reactivity of different subjects. In

1 This work was supported by a grant from the Life Insurance Medical Research Fund.

2 Holder of American College of Physicians Fellowship for Clinical Research (1946-1947). the present study, it has been necessary simply to place reliance on the statement of the subject that he had a sensation of anxiety when the first set of measurements was made and that the sensation had abated or was absent in the control period. It was not feasible to define the emotional state of each subject more exactly than this. An attempt was made to reduce circulatory fluctuations due to causes other than anxiety by conducting control studies under conditions which were otherwise as similar as possible. All subjects were recumbent when studied.

Two groups of subjects were studied. The first group consisted of 23 unselected healthy medical students, ranging in age from 20 to 25 years. Anxiety existed in these subjects because of the imminence of an important academic oral examination. Cardiac output was measured on the Nickerson ballistocardiograph (4) immediately before the examination of each student and again 24 hours after the examination, when anxiety was presumably absent or much abated. Blood pressure by the auscultatory method and pulse rate were determined at the same times. Mean pressure was estimated by adding $1 / 3$ the pulse pressure to the diastolic pressure. In each case, measurements were made at least two hours after the last meal and following a rest period of approximately 20 minutes, the first half of which was spent sitting quietly and the second half recumbent on the ballistocardiograph table. Intercurrent illness was ruled out by a brief history.

The second group of subjects consisted of hospital and clinic patients. In this group cardiac outputs were determined by the Fick method following intracardiac catheterization $(1,5$, and 6$)$. Direct brachial arterial, intracardiac, and pulmonary arterial pressures were recorded by means of a Hamilton manometer, and mean pressures were determined by planimetric integration. Anxiety was first induced by the statement that the procedure, though necessary, involved some risk and by the simulation of a tense and watchful attitude on the part of the observers themselves. The patient was then told that all danger was past, and that the response to the test had been excellent. Occasionally seconal was given in doses of 0.1 to 0.2 gram. In these patients observations were made about one hour apart at a single sitting. In some cases observations were made during light leg exercise with the patient in a recumbent position.

In all cases the peripheral resistance (7) was expressed as the ratio of mean arterial pressure in $\mathrm{mm}$. $\mathrm{Hg}$ to the cardiac index. This is a function proportional to the 
absolute value of the peripheral resistance corrected for the surface area to permit ready comparison of peripheral resistance in persons of different body size.

\section{RESULTS}

\section{Anxiety in normal young males}

The data obtained on the group of 23 students immediately before examination and 24 hours later are summarized in Figure 1. In the pre-examination, or anxious, period each of these subjects admitted to a feeling of tenseness. Subjective observations included most frequently warmth of the face, coldness and sweating of the hands, axillary sweating, palpitation, general shakiness, epigastric uneasiness, and anorexia. There was one report of frank diarrhea and one of frequent urination. Objectively malar flush and clammy hands were most prominent. Tremor of the voice was noted occasionally. In the subsequent control period none of these manifestations of anxiety was present. In general, the attitude was one of relief and satisfaction. There had been no academic failures in this group. Choosing the control observations on each subject as a reference point, the group as a whole during the period of anxiety showed an increase of $10 \%$ in the mean arterial pressure (from 90 to $99 \mathrm{~mm}$. $\mathrm{Hg}$ ), an increase of
$27 \%$ in the heart rate (from 70 to 89 beats/min.), an increase of $16 \%$ in the stroke volume (from 112 to $130 \mathrm{cc}$.), an increase of $48 \%$ in the cardiac index (from 4.2 to 6.2 liters/min./sq.m.), and a fall of $23 \%$ in the peripheral resistance (from 22 to $17 \mathrm{~mm}$. $\mathrm{Hg} /$ liters/min./sq.m.). There was great variation in the amount of change in different individuals between the composed and anxious states. This was particularly true of the cardiac index, as illustrated by Figure 1. In Figure 2 is shown the relation between change in cardiac index and that in peripheral resistance during the anxious state. For each subject the control period is represented by the origin. It will be observed that there is a tendency for correlation between the degree of increase in cardiac index and the degree of fall in peripheral resistance in the anxious state. In general, the greater the increase in cardiac index, the greater the fall in peripheral resistance. In Figure 3, the change in cardiac index in the anxious state is similarly plotted against the change in mean arterial pressure. It is evident that the mean pressure either remained unchanged or increased during the anxious state, but no correlation is evident between the extent of change in the mean pressure and that in the cardiac index.

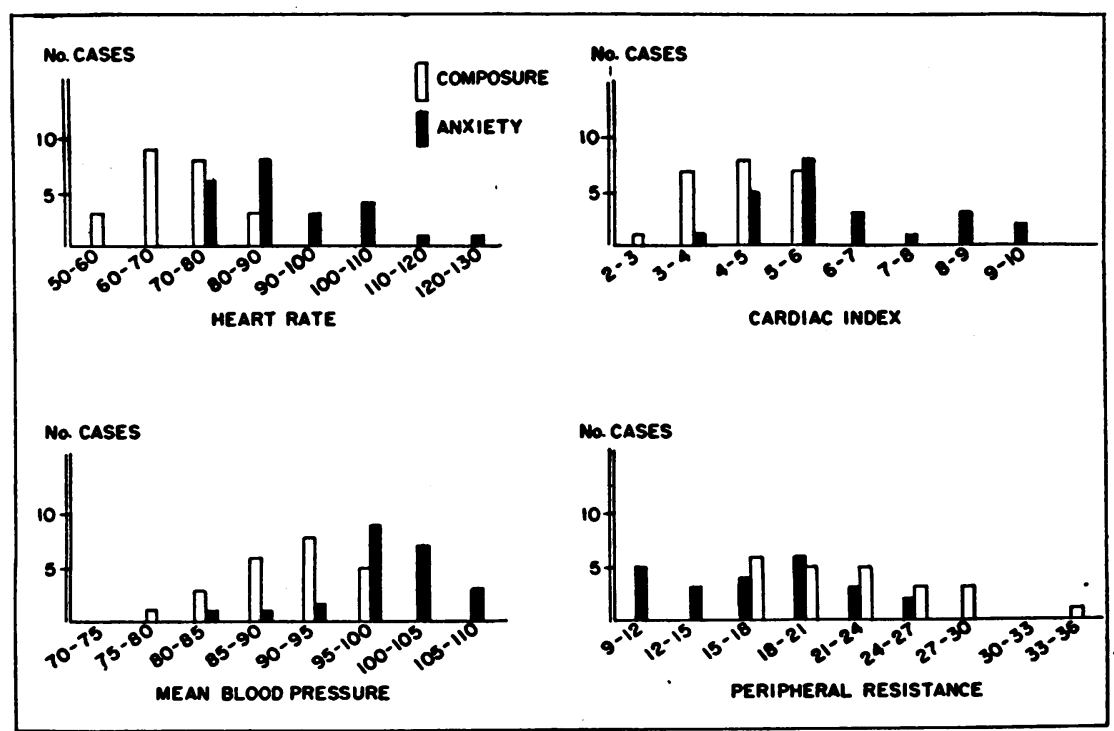

Fig. 1. Effect of Anxiety on Various Circulatory Values in 23 Normal Male Students

Heart rate is expressed in beats/min.; cardiac index in liters/min./sq.m.; mean blood pressure in $\mathrm{mm}$. $\mathrm{Hg}$; and peripheral resistance in $\mathrm{mm}$. $\mathrm{Hg} / \mathrm{liter} / \mathrm{min} . / \mathrm{sq} . \mathrm{m}$. 


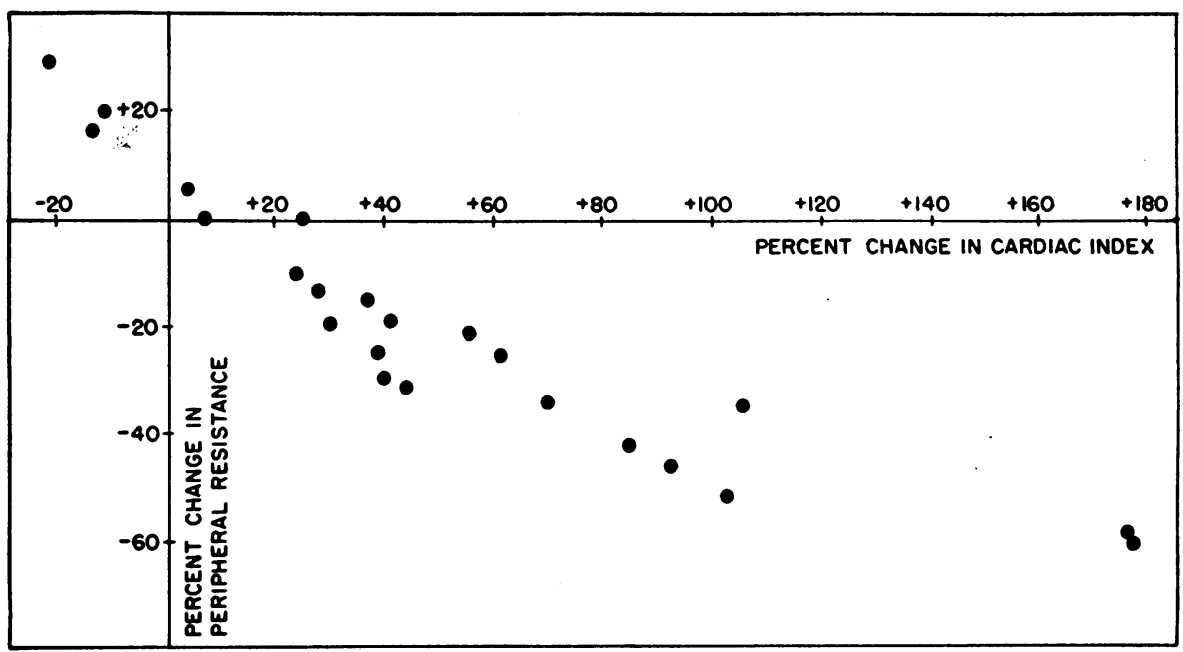

Fig. 2. Relation of Change in Cardiac Index to Change in Peripheral Resistance during the Anxious State in 23 Normal Male Students

The control values for each student during composure are represented by the origin.

For the group, as a whole, the effect of anxiety was to produce a large increase in cardiac index, a large drop in peripheral resistance, and a relatively small rise in mean arterial pressure. The increase in arterial pressure was on the basis of an increased cardiac index rather than an overall vasoconstriction. In four cases, however, the anxious state was associated with a slight to moderate increase in peripheral resistance, and it was primarily or entirely on this basis that the increase in blood pressure occurred. These four cases showed no increase or a slight fall in cardiac index during the anxious state. In three sub- jects who showed increases of cardiac index between 35 and $56 \%$ during the anxious state, there were large moment-to-moment fluctuations in cardiac index as the result of changes in both stroke volume and heart rate. An average value from several determinations has been given in each case.

\section{Observations on hospital and clinic patients}

The second group of subjects, in whom observations were made during intracardiac catheterization, consisted of 12 hospital and clinic patients.

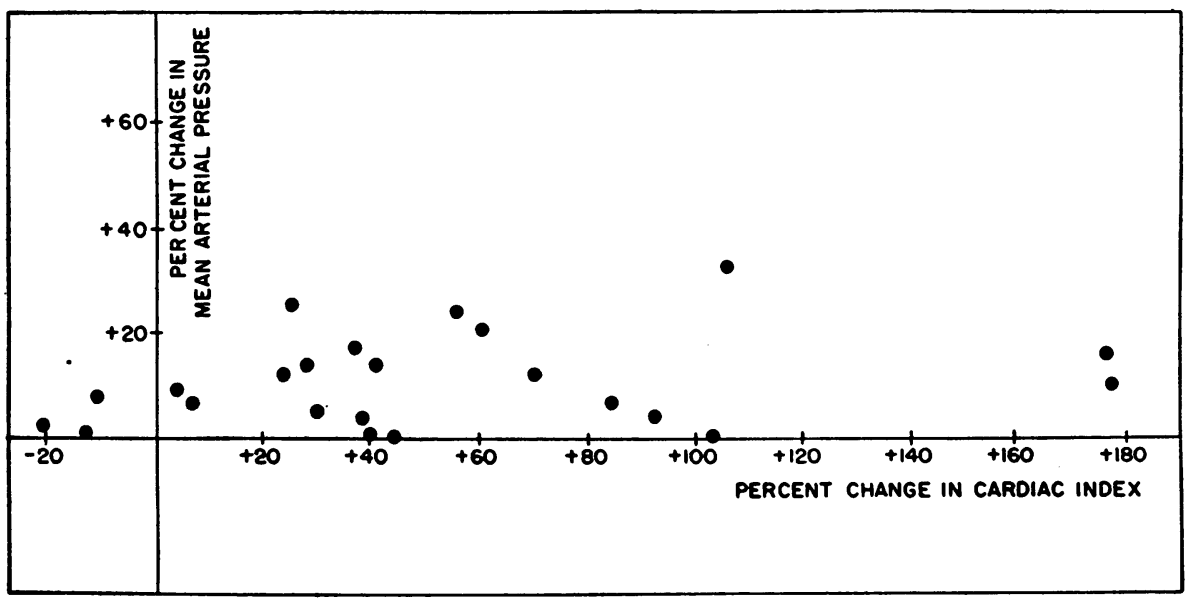

Fig. 3. Relation of Change in Cardiac Index to Change in Mean Arterial. Pressure during the Anxious State in 23 Normal Male Students 
TABLE I

\begin{tabular}{|c|c|c|c|c|c|c|c|c|c|c|c|c|c|}
\hline \multirow{2}{*}{ Patient } & \multirow{2}{*}{ Age } & \multirow{2}{*}{ Sex } & \multirow{2}{*}{ Diagnosis } & \multirow{2}{*}{ State } & \multirow{2}{*}{$\begin{array}{c}\text { Heart } \\
\text { rate }\end{array}$} & \multirow{2}{*}{$\begin{array}{l}\text { Atrial } \\
\text { press. }\end{array}$} & \multirow{2}{*}{$\begin{array}{l}\text { Mean } \\
\text { pulm. } \\
\text { art. } \\
\text { press. }\end{array}$} & \multicolumn{2}{|c|}{$\begin{array}{l}\text { Periph. } \\
\text { art. press. }\end{array}$} & \multirow{2}{*}{$\begin{array}{l}\text { A-V } \\
\text { O2. } \\
\text { diff. }\end{array}$} & \multirow{2}{*}{$\begin{array}{l}\mathrm{O}_{2} \\
\text { con- } \\
\text { sump. }\end{array}$} & \multirow{2}{*}{$\begin{array}{l}\text { Car- } \\
\text { diac } \\
\text { index }\end{array}$} & \multirow{2}{*}{$\begin{array}{l}\text { Periph. } \\
\text { resist. }\end{array}$} \\
\hline & & & & & & & & Sys. dias. & Mean & & & & \\
\hline 1. G. D. & 30 & $\mathbf{M}$ & $\begin{array}{l}\text { Asymptomatic CNS } \\
\text { syphilis }\end{array}$ & & $\begin{array}{l}73 \\
82\end{array}$ & $\underset{H \boldsymbol{g}}{m_{\boldsymbol{g}}}$ & $\begin{array}{c}\underset{H}{m} . \\
12 \\
14 \\
14\end{array}$ & $\begin{array}{c}\underset{H \boldsymbol{g}}{\mathrm{m} .} \\
140 / 88 * \\
110 / 80^{*}\end{array}$ & $\begin{array}{r}m m . \\
H g \\
105 \\
90\end{array}$ & $\begin{array}{c}\text { ool. \% } \\
2.9 \\
6.0\end{array}$ & $\begin{array}{c}c c . / \\
\text { min.l } \\
\text { sq. m. } \\
141 \\
314\end{array}$ & 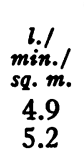 & 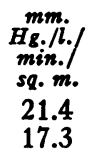 \\
\hline 2. W. H. & 15 & $\mathbf{M}$ & Latent syphilis & $\begin{array}{l}\text { Anxiety } \\
\text { Exercise }\end{array}$ & $\begin{array}{l}62 \\
72\end{array}$ & $\begin{array}{l}4 \\
5\end{array}$ & $\begin{array}{l}12 \\
14\end{array}$ & $\begin{array}{r}95 / 53 \\
119 / 67\end{array}$ & $\begin{array}{l}68 \\
87\end{array}$ & $\begin{array}{l}3.1 \\
5.8\end{array}$ & $\begin{array}{l}177 \\
387\end{array}$ & $\begin{array}{l}5.7 \\
6.7\end{array}$ & $\begin{array}{l}11.9 \\
13.0\end{array}$ \\
\hline 3. T. C. & 44 & $\mathrm{M}$ & 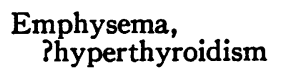 & & $\begin{array}{l}114 \\
114\end{array}$ & 0 & $\begin{array}{l}18 \\
22\end{array}$ & $\begin{array}{l}133 / 74 \\
150 / 79\end{array}$ & 92 & $\begin{array}{l}3.4 \\
6.5\end{array}$ & $\begin{array}{l}220 \\
285\end{array}$ & $\begin{array}{l}6.5 \\
4.4\end{array}$ & $\begin{array}{l}14.1 \\
22.2\end{array}$ \\
\hline 4. C. N. & 35 & F & Methemoglobinemia & $\begin{array}{l}\text { Anxiety } \\
\text { Exercise }\end{array}$ & $\begin{array}{l}89 \\
80\end{array}$ & 4 & $\begin{array}{l}18 \\
20\end{array}$ & $128 / 70 *$ & 89 & $\begin{array}{l}3.1 \\
4.5\end{array}$ & $\begin{array}{l}205 \\
284\end{array}$ & $\begin{array}{l}6.7 \\
6.4\end{array}$ & 13.4 \\
\hline 5. F. J. & 24 & $\mathbf{M}$ & A-V fistula & $\begin{array}{l}\text { Anxiety } \\
\text { Composure }\end{array}$ & $\begin{array}{l}83 \\
72\end{array}$ & $\begin{array}{l}2 \\
2\end{array}$ & $\begin{array}{l}14 \\
13\end{array}$ & & $\begin{array}{l}91 \\
91\end{array}$ & $\begin{array}{l}3.1 \\
3.8\end{array}$ & $\begin{array}{l}179 \\
172\end{array}$ & $\begin{array}{l}5.7 \\
4.5\end{array}$ & $\begin{array}{l}15.9 \\
20.2\end{array}$ \\
\hline 6. S. C. & 44 & $\mathbf{M}$ & Hypertension & ty & $\begin{array}{l}79 \\
75\end{array}$ & & $\begin{array}{r}16 \\
9\end{array}$ & $\begin{array}{l}102 \\
115\end{array}$ & $\begin{array}{l}137 \\
142\end{array}$ & $\begin{array}{l}2.6 \\
4.3\end{array}$ & $\begin{array}{l}171 \\
163\end{array}$ & $\begin{array}{l}6.7 \\
3.8\end{array}$ & $\begin{array}{l}20.4 \\
37.4\end{array}$ \\
\hline 7. E. H. & 35 & F & Hypertension & $\begin{array}{l}\text { Anxiety } \\
\text { Composure }\end{array}$ & $\begin{array}{l}60 \\
66\end{array}$ & 3 & $\begin{array}{r}8 \\
10\end{array}$ & $\begin{array}{l}202 / 108 \\
190 / 113\end{array}$ & $\begin{array}{l}153 \\
142\end{array}$ & $\begin{array}{l}5.1 \\
4.4\end{array}$ & $\begin{array}{l}127 \\
123\end{array}$ & $\begin{array}{l}2.5 \\
2.8\end{array}$ & $\begin{array}{l}61.2 \\
50.7\end{array}$ \\
\hline 8. O. T. & 55 & $F$ & $\begin{array}{l}\text { Aortic insufficiency, } \\
\text { syphilis }\end{array}$ & $\begin{array}{l}\text { Anxiety } \\
\text { Composure } \\
\text { Exercise }\end{array}$ & \begin{tabular}{r|}
78 \\
77 \\
100
\end{tabular} & $\begin{array}{l}0 \\
3\end{array}$ & $\begin{array}{r}6 \\
10 \\
19\end{array}$ & & $\begin{array}{r}84 \\
84 \\
120\end{array}$ & $\begin{array}{l}5.4 \\
3.0 \\
4.6\end{array}$ & $\begin{array}{l}139 \\
126 \\
413\end{array}$ & $\begin{array}{l}2.6 \\
4.3 \\
9.0\end{array}$ & $\begin{array}{l}32.3 \\
19.5 \\
13.3\end{array}$ \\
\hline 9. E. C. & 21 & F & $\begin{array}{r}\text { Convalescent } \\
\text { pneumonia }\end{array}$ & \begin{tabular}{|l|} 
Anxiety \\
Composure \\
Exercise
\end{tabular} & $\begin{array}{l}82 \\
92\end{array}$ & 1 & $\begin{array}{l}9 \\
9\end{array}$ & & $\begin{array}{l}80 \\
84\end{array}$ & $\begin{array}{l}4.4 \\
4.1 \\
6.8\end{array}$ & $\begin{array}{l}142 \\
126 \\
285\end{array}$ & $\begin{array}{l}3.2 \\
3.1 \\
4.2\end{array}$ & $\begin{array}{l}25.0 \\
27.0\end{array}$ \\
\hline 10. C. B. & 41 & $\mathbf{M}$ & $\begin{array}{l}\text { Congestive failure, } \\
\text { etiology unknown }\end{array}$ & $\begin{array}{l}\text { Anxiety } \\
\text { Composure }\end{array}$ & & & & & & $\begin{array}{l}8.3 \\
6.2\end{array}$ & $\begin{array}{l}170 \\
153\end{array}$ & $\begin{array}{l}2.1 \\
2.5\end{array}$ & \\
\hline 11. C. Br. & 54 & F & $\begin{array}{l}\text { Congestive failure, } \\
\text { syphilitic AI }\end{array}$ & osure & $\begin{array}{l}78 \\
68\end{array}$ & 0 & $\begin{array}{l}15 \\
12\end{array}$ & $\begin{array}{l}179 / 57 \\
180 / 53\end{array}$ & $\begin{array}{r}103 \\
97\end{array}$ & $\begin{array}{l}7.5 \\
6.0\end{array}$ & $\begin{array}{l}138 \\
122\end{array}$ & $\begin{array}{l}1.8 \\
2.0\end{array}$ & $\begin{array}{l}57.3 \\
48.5\end{array}$ \\
\hline 12. G. S. & 47 & $\mathbf{M}$ & $\begin{array}{l}\text { Congestive failure, } \\
\text { syphilitic AI }\end{array}$ & \begin{tabular}{|l|} 
Anxiety \\
Composure \\
Exercise
\end{tabular} & $\begin{array}{l}77 \\
68 \\
84\end{array}$ & $\begin{array}{r}-2 \\
5\end{array}$ & $\begin{array}{l}37 \\
25 \\
54\end{array}$ & $\begin{array}{l}153 / 51 \\
149 / 55 \\
193 / 62\end{array}$ & $\begin{array}{r}87 \\
88 \\
108\end{array}$ & $\begin{array}{l}5.7 \\
6.7 \\
7.0\end{array}$ & $\begin{array}{l}148 \\
120 \\
210\end{array}$ & $\begin{array}{l}2.1 \\
2.2 \\
3.0\end{array}$ & $\begin{array}{l}41.5 \\
40.0 \\
36.0\end{array}$ \\
\hline
\end{tabular}

* Auscultatory.

The data obtained on these subjects are presented in Table I. In most cases, an attempt was made to induce anxiety during the early part of the procedure. In the remainder, anxiety was spontaneous. All subjects admitted to a feeling of tenseness or apprehension. All subjects are included in whom an attempt was made to induce anxiety during the course of this study.

The relation between rate of oxygen consumption and cardiac index is shown in Figure 4. In this figure, the rectangle indicates the range covered by 18 basal subjects observed by Stead et al. (1). The area inclosed by the two straight lines drawn to the extremities of the rectangle indicates the range covered by subjects with a nor- mal cardiovascular system studied by Hickam and Cargill (8) during rest and exercise. It is believed that points falling within the region so inclosed are indicative of a normal response of the cardiac index to the body oxygen requirement. Points to the right of the area represent an unusually high cardiac index, and those to the left indicate an unusually low cardiac index in proportion to the oxygen consumption.

For convenience in presentation, the present group is subdivided according to the procedure followed and the condition of the patient.

Anxiety followed by exercise. In cases 1, 2, 3, and 4, observations were made during the anxious state and then during a period of light leg 


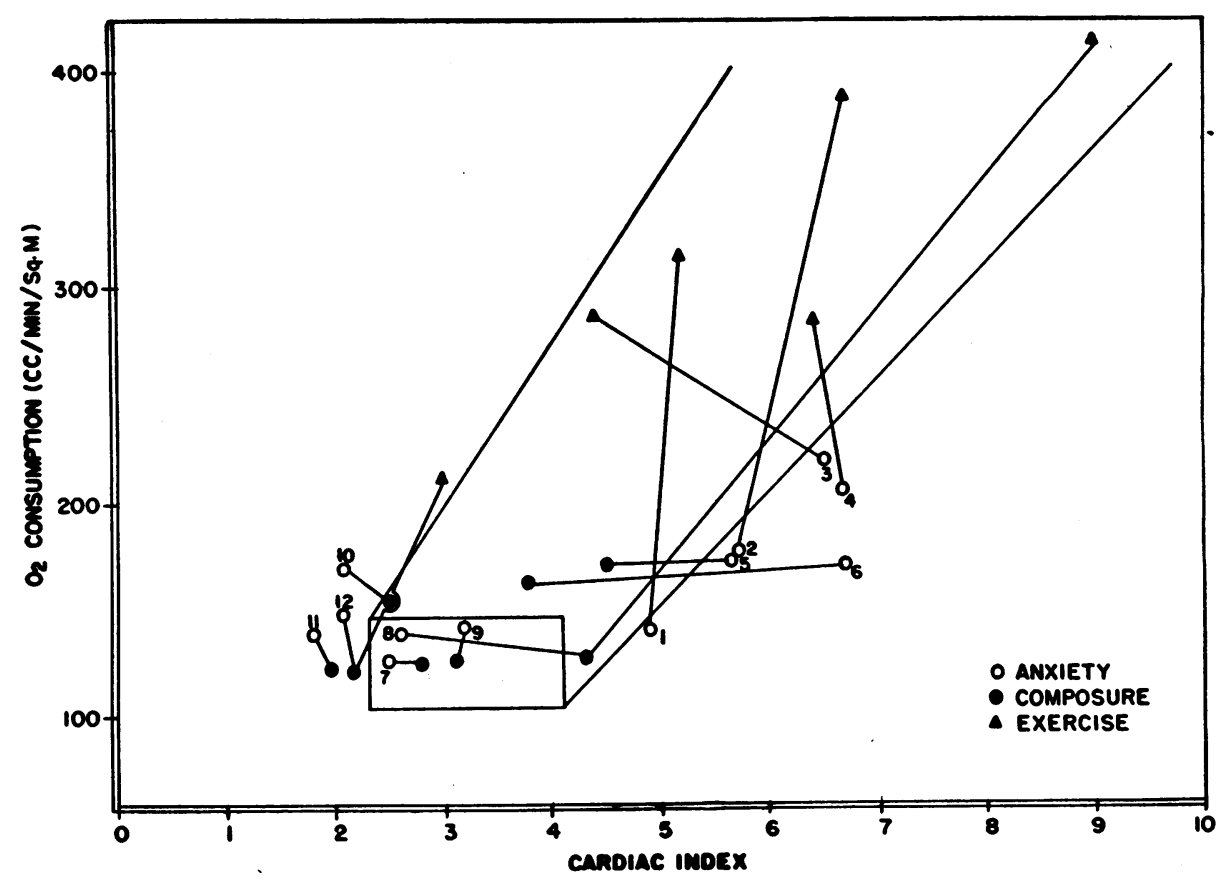

Fig. 4. Relation of Cardiac Index to Oxygen Consumption in Subjects in States of ANxiety, Composure, and Muscular Exercise

Connecting lines identify points belonging to the same subject. Rectangle covers normal basal range-lines from extremities of rectangle cover range of values exhibited by normal persons during muscular exercise.

exercise which followed immediately. Patients 1 and 2 had asymptomatic syphilis, without evidence of cardiovascular disease. Patient 3 had pulmonary emphysema. Because of a consistent elevation of the BMR hyperthyroidism was suspected. Patient 4 complained of weakness and cyanosis and was found to have methemoglobinemia, apparently on the basis of ingestion of drugs containing acetanilid. Patients 3 and 4 both had dyspnea on moderate exertion, but in neither case was there any cardiac enlargement. All four patients, as is evident in Figure 4, had a cardiac index during the anxious state which was abnormally high for the rate of oxygen consumption. During the subsequent exercise period, however, the relation between cardiac index and oxygen consumption shifted to the normal range. In patients 1 and 2 exercise resulted in a very slight increase of cardiac output over the previous level, while in patients 3 and 4 the increased oxygen consumption caused by exercise was associated with an actual fall in cardiac output.

Anxiety followed by composure. In cases 5, 6, 7,8 , and 9 the initial observations, which were made while the patients were considered to be in an anxious state, were followed by a period of rest and reassurance. Seconal in doses of 0.1 to 0.2 gram was given by mouth. After an hour observations were repeated. These patients were all in the post-absorptive state and had been at complete physical rest for at least half an hour before the first observations were made. Case 5 had a traumatic A-V fistula; 6 and 7 had essential hypertension; 8 had syphilitic aortic regurgitation; 9 was convalescent from pneumonia. There was no evidence of cardiac decompensation in any of these patients.

The behavior of cases 5 and 6 was similar to that of most of the normal students. As indicated in Figure 4 the cardiac index was abnormally high in proportion to the rate of oxygen consumption during the period of anxiety. On composure, the cardiac index fell, assuming a normal relation to the oxygen consumption. During anxiety the peripheral resistance was lower than during composure. The mean arterial pressure showed little change.

The behavior of cases 7 and 8 was opposite to 
that expected. In both cases the peripheral resistance was higher during the period of anxiety than during composure. During anxiety patient 7 , who had essential hypertension, had a moderate increase of mean arterial pressure over the control level, but no important change in cardiac index or oxygen consumption. During anxiety patient 8 had no change in pressure but the cardiac index was well below the control level. In this patient oxygen consumption during anxiety was $13 \%$ above the control level. Both patients stated that they experienced some anxiety during the first period of observation and relative composure during the second. It is primarily on the basis of this statement that their cardiovascular reactions are assigned respectively to states of anxiety and composure. The reaction of these patients appears to be similar to that of the four students who, during anxiety, had a rise in peripheral resistance and no change or a fall in cardiac index.

Patient 9 showed no important change in peripheral resistance or cardiac index between the two periods, but the rate of oxygen consumption was $10 \%$ higher during anxiety than during composure.

Anxiety in patients with cardiac decompensation. Patients 10,11, and 12 had recently had congestive heart failure, of unknown etiology in case 10 , and the result of syphilitic aortic regurgitation in the other two. All had improved to the extent of being comfortable while flat in bed. As indicated in Figure 4, the cardiac output of these patients was abnormally low for the rate of oxygen consumption. In the period of anxiety the rate of oxygen consumption was increased by 11,14 , and $23 \%$, respectively, over that in the period of composure. There were, however, no substantial changes in cardiac output or peripheral resistance between the two periods. The data on the subsequent exercise period of patient 12 indicate that his ability to increase his cardiac output was extremely limited, as is typical of persons with cardiac decompensation. Mean pulmonary arterial pressures were measured in patients 11 and 12 . In patient 11 , in whom the pulmonary pressure was not abnormally elevated, there was no substantial change as the result of anxiety. This was generally true for the patients without cardiac decompensation. In case 12 , however, in whom the pulmonary pressure was abnormally elevated during the period of composure, there was a $50 \%$ increase in pressure during the period of anxiety. In the exercise period there was a $100 \%$ increase in pressure. Pulmonary pressure tracings from this patient are reproduced in Figure 5.

\section{DISCUSSION}

In attempting to compare values for cardiac output in different subjects, it is customary to make observations at complete physical rest. It is obvious that physical rest does not mean emotional relaxation and that because of this fact, widely divergent values for cardiac output are obtained even when the figures are reduced to the same surface area. The scatter of the values was re-

\section{PULMONARY PRESSURES}

A. $\mathrm{L}$

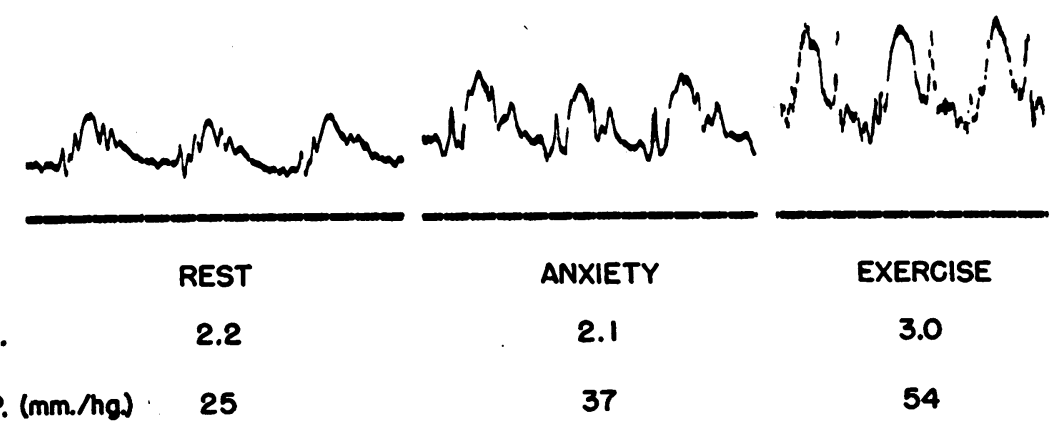

M.P. (mm./hg) $\quad 25$

Fig. 5. Influence of Anxiety and Muscular Exercise on Pulmonary
Arterial Pressure in a Patient with Congestive Heart Failure Resulting From AORTIC INSUFFICIENCY 
duced by light exercise. It appears that resting values are by no means the most constant values.

The data recorded here, together with that reported elsewhere, demonstrate the great variability in the response of the circulation to anxiety. This variability is qualitative as well as quantitative. Stimuli from the emotional content of thought may pass out over both sympathetic and parasympathetic portions of the autonomic nervous system. The autonomic nervous system may affect the heart by altering its rate and output, and the peripheral vessels by causing vasoconstriction or vasodilatation. In addition to the direct effects on the circulation from such stimuli, there may be indirect effects. For example, a lowering of the peripheral resistance causes an immediate rise in cardiac output, the mechanism of which has not been determined. At present, there is no way of determining which changes in the circulation result from stimuli from the emotional content of thought acting directly on the heart and which are secondary to changes in the peripheral vessels with secondary effect on the heart.

In most subjects the cardiovascular effects of anxiety are similar to those produced by small doses of epinephrine (9). The heart rate and cardiac output are increased. There is a moderate elevation of blood pressure, but the peripheral resistance (ratio of mean arterial pressure to cardiac output) is decreased, apparently indicating a predominant dilatation of the vascular bed. The vessels of the hands and feet are constricted. There is a moderate increase in rate of oxygen consumption.

In certain subjects, severe anxiety may be attended by circulatory collapse (10). In such cases the overall peripheral resistance is decreased, as in the type of reaction described above, but the heart rate is slowed and the cardiac output does not increase in the expected fashion as the peripheral resistance decreases. There results a profound fall of blood pressure. Both types of reactions have been observed in the same subject at different times. Both reactions appear to have in common an overall decrease in vascular tone, together with evident vasoconstriction in certain regions, such as the hands and feet. In the first type of reaction, however, the general decrease in vascular tone is compensated by an increase in cardiac output, so that the blood pressure is maintained at the control level, or, more commonly, elevated slightly above the controi level. In the second type of reaction there is no compensatory increase in cardiac output, so that the blood pressure falls as the vascular tone decreases. The sweating and hyperperistalsis which accompany the collapse reaction are signs of cholinergic stimulation and suggest that the cardiac rate is inhibited by strong vagal activity. Lewis (11) found that the administration of atropine prevented the fall in heart rate but not the drop in blood pressure.

In the present study there was a small group of subjects who demonstrated a third type of cardiovascular reaction to anxiety. In this group there was an overall increase in vascular tone. The blood pressure was maintained at or above the control level, while the cardiac output fell. The heart rate showed no material change or a moderate increase.

The extent of the fall in peripheral resistance which can occur in the anxious state is a phenomenon almost as striking as the increase in cardiac output. In contrast the mean blood pressure, which may be expressed as the product of the cardiac output and peripheral resistance, changes relatively little. The moderate elevation of blood pressure commonly seen in anxiety in normal persons usually represents a relatively slight imbalance between a large increase in cardiac output and a large fall in peripheral resistance. Starr (12) has described a group of persons with hyperactive circulation and a moderate elevation of blood pressure. He points out that in these persons the elevation of blood pressure is on the basis of an increased cardiac output, while in persons with essential hypertension the peripheral resistance is increased and the cardiac output is normal or even sub-normal. It is to be emphasized, however, that increases of blood pressure in normal persons during anxiety are of only moderate degree. Normally, the peripheral resistance and cardiac output are so adjusted during anxiety as to prevent any large change in mean arterial pressure. Failure to accomplish such an adjustment may, in itself, be indicative of arterial dysfunction.

There is considerable evidence that various patterns of vasoconstriction and vasodilatation may 
be centrally set up in response to different stimuli to the nervous system. The Lovēn reflex, in which stimulation of afferent fibers from an organ produces generalized vasoconstriction. and localized vasodilatation, is an example of this phenomenon. Emotional blushing reactions of the skin and intestinal mucosa are further examples of a localized vasodilatation resulting from a central stimulus. On the other hand, pain produced by the immersion of an extremity in ice water may be associated with a large increase in peripheral resistance and an elevation in blood pressure without any apparent localized regions of vasodilatation. While it is true that the vasomotor pathways through the sympathetic chain normally exhibit a strong constrictor tone, it is apparent this tone can be increased or decreased in various anatomic patterns by the vasomotor centers in response to different stimuli.

There appears no need to postulate that emotional stimuli which may incite activity of the sympathetic nervous system need be associated with generalized vasoconstriction or with any fixed vascular pattern. It seems likely that further experience with anxious subjects will demonstrate additional types of cardiovascular reactions.

The nature and location of the vascular channels through which the excess quantity of blood circulates in those persons who develop a hyperactive circulation in response to anxiety is a problem of considerable interest. The disproportion of cardiac output to oxygen consumption and the high oxygen content of mixed venous blood suggest that a considerable portion of the output is shunted through arterio-venous connections or preferential channels thus by-passing the capillaries. There appears to be no present evidence to indicate the organs in which such shunts $/$ are occurring.

The extent of the extra cardiac work which may be imposed by anxiety is impressive. The average cardiac index of the student group (nonbasal) was elevated from 4.2 in the control period to 6.2 in the anxious period. From previous studies of the normal response of the cardiac output to the oxygen requirements of the body, it is estimated that this increase in cardiac output corresponds very roughly to that which would be demanded by an increase in oxygen consump- tion equal to the basal metabolism. The extra cardiac work imposed by anxiety may well be a contributory factor in the production of attacks of angina pectoris during physical rest in persons with impaired coronary circulation.

Previous studies have shown that patients with congestive heart failure at rest have an abnormal response to exercise. They have a small increase or an actual decrease in cardiac output and a marked rise in pulmonary arterial pressure. The rise in pulmonary arterial pressure seems to be related to the inability of the left ventricle normally to increase its output and probably in part represents a rise in left atrial and pulmonary capillary pressures. In view of the abnormal response to exercise, a stimulus normally causing a rise in cardiac output, it would be logical to expect an abnormal response to anxiety, a stimulus again normally causing a rise in cardiac output. In one patient with congestive failure. anxiety caused changes similar to but less marked than those produced by exercise. It is suggested that in certain patients with heart failure acute attacks of pulmonary edema may be precipitated by anxiety because of the disturbance in pulmonary pressures from the inability of the left ventricle to respond normally. This mechanism may be responsible for some of the attacks of acute pulmonary edema precipitated by procedures as thoracentesis, abdominal paracentesis, catheterization, or lumbar puncture.

\section{SUMMARY AND CONCLUSIONS}

1. In the majority of persons, anxiety has an effect on the circulation similar to that produced by small doses of epinephrine. The cardiac output, heart rate, and oxygen consumption are increased. There is a moderate elevation of blood pressure, but the peripheral resistance is decreased. The cardiac output is abnormally high in proportion to the rate of oxygen consumption. When persons with this reaction undertake muscular exercise, the normal relation between cardiac output and rate of oxygen consumption is re-established.

2. In certain subjects anxiety may be attended by circulatory collapse. In such cases the peripheral resistance is decreased, but the compensatory increase in cardiac output fails to occur, with a resultant fall of blood pressure to low levels. 
3. In a small group of subjects anxiety results in an increase in peripheral resistance and an elevation of blood pressure, with no change or a fall in cardiac output.

\section{BIBLIOGRAPHY}

1. Stead, E. A., Jr., Warren, J. V., Merrill, A. J., and Brannon, E. S., The cardiac output in male subjects as measured by the technique of right atrial catheterization. Normal values with observations on the effect of anxiety and tilting. J. Clin. Invest., 1945, 24, 326.

2. Wolf, G. A., Jr., and Wolff, H. G., Studies on the nature of certain symptoms associated with cardiovascular disorders. Psychosom. Med., 1946, 8, 293.

3. Mainzer, F., and Krause, M., The influence of fear on the electrocardiogram. Brit. Heart J., 1940, $2,221$.

4. Nickerson, J. L., Symposium on cardiac output; the low frequency, critically-damped ballistocardiograph. Federation Proc., 1945, 4, 201.

5. Padilla, T., Cossio, P., and Berconsky, I., Sondeo del corazón; determinacion del volumen minuto circulatorio. Semana méd., 1932, 2, 445.

6. Cournand, A., and Ranges, H. A., Catheterization of the right auricle in man. Proc. Soc. Exper. Biol. \& Med., 1941, 46, 462.
7. Aperia, A., Hemodynamical Studies, Skandinavisches Archiv für Physiologie, Supplement 16 (to vol. 83), p. 35, 1940.

8. Hickam, J. B., and Cargill, W. H., Effect of exercise on cardiac output and pulmonary arterial pressure in normal persons and in patients with cardiovascular disease and pulmonary emphysema. $J$. Clin. Invest., 1948, 27, 10.

9. Starr, I., Gamble, C. J., Margolies, A., Donal, J. S., Jr., Joseph, N., and Eagle, E., A clinical study of the action of 10 commonly used drugs on cardiac output, work and size; on respiration, on metabolic rate and on the electrocardiogram. J. Clin. Invest., 1937, 16, 799.

10. Warren, J. V., Brannon, E. S., Stead, E. A., Jr., and Merrill, A. J., The effect of venesection and the pooling of blood in the extremities on the atrial pressure and cardiac output in normal subjects with observations on acute circulatory collapse in three instances. J. Clin. Invest., 1945, 24, 337.

11. Lewis, T., Lecture on vasovagal syncope and the carotid sinus mechanism, with comments on Gowers' and Nothnagel's syndrome. Brit. Med. J., 1932, 1,873 .

12. Starr, I., Ballistocardiographic studies of draftees rejected for neurocirculatory asthenia. War. Med., 1944, 5, 155.

\section{LETTER FROM THE EDITORS}

It may be of general interest to the contributors and subscribers to explain some of the vicissitudes of the editors, the problems of the mechanics of editing and printing the Journal and at times to introduce miscellaneous topics for attention and comment. This procedure reverses the customary letter to the editors in which they are targets for criticism or correction-enough comments still come in to remind us that we are not infallible.

Assuming that an article submitted is worthy of publication, it follows that the sooner it appears in print the better, not just for the credit of priority but for the spread of information in fields of investigation where the advance is rapid. The usual processing of manuscripts begins with their examination by each of the editors, discussion at a weekly meeting and except in rare instances, the selection of a minimum of two reviewers for careful criticism. This initial processing takes one or two weeks, and averages about ten days. Reviewers are asked to return the manuscripts within 14 days, and this has been adhered to with increasing frequency; the average now is two weeks while formerly it was slightly more than four weeks. The submission of two copies of a manuscript has reduced the time spent by editors and reviewers by nearly half, so that final action may be taken on a paper within three weeks whereas formerly the minimum was five or six weeks.

In a representative issue approximately one-third of the accepted articles do not require alteration or revision. The remainder may require slight or extensive change, and on the average this has taken just over five weeks with extremes of one to 15 weeks.

Copy is sent to the printer ten weeks before the first day of the month of issue. While it may be possible to shorten this period of typesetting, return and correction of galley proofs and page proofs, and finally printing and distributing the Journal, this has not been done so far. Assuming that a manuscript went through the stages in the shortest possible time it might appear in the Journal in just over three months and we have had a few appear less than four months after they were received. The average time elapsing for articles in the last issue was just under six months. This is approximately the same time as for two random numbers in 1940, a sample pre-war year, and it compares with a period of about ten months in the war year 1944, when the Journal was actually mailed much later than the month noted on it.

This brief survey may clarify to those not familiar with the problem some of the reasons why papers do not get printed more rapidly. We are actually approaching very favorable elapsed time performance in handling manuscripts, and for this we must give credit to our reviewers as well as the contributors. We hope for even more improvement, but there is a minimum beyond which we cannot go. 